\title{
Developing multidimensional measures of healthy food access among low-income adults in Cleveland, Ohio, USA
}

\author{
Susan A Flocke ${ }^{1,2,3, *}$, Punam Ohri-Vachispati ${ }^{4}$, En-Jung Shon ${ }^{1}$, Erika S Trapl ${ }^{1,3}$, \\ Elaine Borawski ${ }^{1,3}$, Kristen Matlack ${ }^{1}$ and Darcy A Freedman ${ }^{1,3}$ \\ 'Prevention Research Center for Healthy Neighborhoods, Case Western Reserve University, Cleveland, OH, USA: \\ ${ }^{2}$ Department of Family Medicine and Community Health, Case Western Reserve University, 11000 Cedar Avenue, \\ Suite 402, Cleveland, $\mathrm{OH}$ 44106-7136, USA: ${ }^{3}$ Department of Population and Quantitative Health Sciences, Case \\ Western Reserve University, Cleveland, OH, USA: ${ }^{4}$ School of Nutrition and Health Promotion, Arizona State \\ University, Tempe, AZ, USA
}

Submitted 27 January 2017: Final revision received 21 June 2017: Accepted 28 June 2017: First published online 29 August 2017

\begin{abstract}
Objective: Access to nutritious foods is key to achieving health promotion goals. While there is evidence that nutritious food access is complex, measures assessing multiple domains of access, including spatial-temporal, economic, social, service delivery and personal, are lacking. The current study evaluates psychometric properties of scales designed to measure perceptions of multiple domains of nutritious food access among low-income populations.

Design: A cross-sectional survey was conducted in 2015. Eighty-one items were selected or developed to represent five domains of nutritious food access for food shopping overall and specific to shopping at farmers' markets. Evaluation of the items included exploratory factor analysis within each domain and internal consistency reliability for each of the sub-scales.

Setting: Data were collected in seventeen urban neighbourhoods in Greater Cleveland, Ohio, USA that have high levels of poverty. All participants had access to at least one farmers' market within $1.6 \mathrm{~km}$ ( 1 mile) of their home to standardize spatial access to nutritious foods.

Subjects: Adults ( $n$ 304) receiving Supplemental Nutrition Assistance Program benefits.

Results: Each domain included multiple sub-domains: spatial-temporal (four), service delivery (two), economic (two), social (three) and personal (three), for a total of fourteen subdomains. The internal consistency reliability for one of the sub-domains was outstanding (>0.90), seven were excellent $(0 \cdot 80-0 \cdot 89)$, five were very good (0.70-0.79) and one scale had poor reliability (0.58).

Conclusions: Multiple sub-domains of nutritious food access can be assessed using short measures that have been tested for internal consistency. These measures are suitable for assessing the complex phenomena of nutritious food access among low-income populations.
\end{abstract}

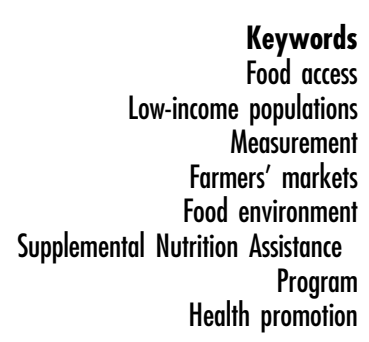

The prevalence of obesity is high and rising not only in the USA but also globally, with rates disproportionately higher for low-income populations ${ }^{(1,2)}$. While multiple factors influence obesity risk, research focused on obesogenic environments illuminates that improving access to nutritious foods is a key target for intervention ${ }^{(3,4)}$. Nutritious food is generally defined as fruits, vegetables, whole grains and other nutrient-dense foods to promote overall health $^{(5)}$. This is particularly important for low-income populations living in communities with low spatial access to full-service supermarkets selling a wide variety of nutritious foods and with high access to smaller stores and fast-food restaurants selling convenience foods that are higher in energy and low in nutritional value ${ }^{(6-9)}$. Moreover, food prices and quality also vary within community food environments, with patterns of inequity occurring along lines of racial and socio-economic composition of communities $^{(10-13)}$. Obesity prevention interventions that include strategies to address some of these nutritious food access barriers within community settings have been found to be more effective among low-income populations compared with interventions focused on changing individual-level factors ${ }^{(14)}$. To maximize the effect of community food environment interventions, it is important 
to develop measures to assess multiple factors within food environments to evaluate mechanisms of influence and guide intervention planning.

The most common method for assessing community food environments is through geographic analysis of food stores within a targeted context to capture a measure of spatial access ${ }^{(15,16)}$. Geographic analysis methods include in-store observations of food availability, quality, price and/or marketing ${ }^{(17-19)}$, analysis of the balance of food retailers in a specific context based on secondary data sources of food businesses ${ }^{(20)}$, and assessment of selfreported perceptions of the food environment ${ }^{(10,21,22)}$. While geographic access is one component of the community food environment, there is a need to establish measures to systematically evaluate food access from a multidimensional framework of food access ${ }^{(23,24)}$.

A multidimensional framework of nutritious food access developed by Freedman and colleagues provides a model for generating measures related to five domains of nutritious food access, including spatial-temporal, economic, service, social and personal ${ }^{(25)}$. Informed by qualitative data, this multidimensional framework highlights different types of access needed to foster nutritious food choices in community food environments ${ }^{(16)}$. For instance, while a community food environment may have several food retailers available (spatial-temporal) offering a variety of foods at affordable prices (economic), the stores may not be socially acceptable (social) or welcoming (service) or may not offer food products needed for personal health needs (personal), thereby constraining nutritious food choice. Given the importance of nutritious food access to obesity prevention and health promotion, there is a need for valid and reliable measures that assess the complexity of this phenomenon to not only examine need, but also to evaluate interventions intended to improve community food environments.

The present study aimed to develop and evaluate psychometric properties of scales designed to measure perceptions of the five domains of the Freedman multidimensional nutritious food access framework among lowincome populations. Measure development was shaped by two considerations in the current research. First, given the growing emphasis on the utility of farmers' markets to fill the gap in nutritious food access in low-income urban settings ${ }^{(26,27)}$, the research goal was to develop and test the psychometric properties of a comprehensive measure of nutritious food access with an emphasis on fresh fruits and vegetables that included items explicitly focused on farmers' markets in the community food environment, in addition to assessing other food retailers. Second, because lack of access to nutritious food and obesity disproportionately burden low-income populations, measures were developed specifically for people living in low-income neighbourhoods receiving federal nutrition assistance benefits (i.e. individuals receiving Supplemental Nutrition Assistance Program (SNAP) benefits). Given the context of the present study, measure development with this population is designed to promote relevance and utility for future research targeting community food environments as a strategy to reduce obesity disparities in low-income populations.

\section{Methods}

\section{Study setting}

The current research occurred in Cleveland and East Cleveland, Ohio, USA; cities adjacently located with a total of about 400000 residents. Most residents in Cleveland (53.3\%) and East Cleveland (93.2\%) identify as African American $^{(28)}$ and a substantial portion of the households in Cleveland (34.5\%) and East Cleveland (43.5\%) receive SNAP benefits ${ }^{(28)}$. The measurement development that is the focus of the present analysis was part of formative research to guide a study aimed at improving healthy food access in the two study cities by increasing use of farmers' markets among SNAP recipients. These cities offer a unique context to evaluate multidimensional measures of nutritious food access among low-income urban residents for three key reasons. First, these cities have high rates of poverty, with $31 \%$ of households in Cleveland and $42 \%$ of households in East Cleveland having annual income below \$US $14999^{(28)}$. Second, the majority of the census tracts in these cities are defined by the US Department of Agriculture $^{(29)}$ as 'food deserts', indicating that most census tracts have low spatial access to full-service supermarkets within $0.8 \mathrm{~km}(0.5$ miles $)$. Finally, these cities have addressed food access challenges through wide-scale implementation of farmers' markets ${ }^{(30)}$.

\section{Geographic sampling}

Sampling focused first on identifying the targeted geographic area and then study participants who met specific inclusion requirements. The goal was to identify and enrol individuals who lived within $1.6 \mathrm{~km}$ ( 1 mile) of a farmers' market to ensure a minimal level of spatial access to at least one food retailer offering nutritious choices. Geographic sampling occurred by mapping all farmers' markets in Greater Cleveland in ArcGIS version 10.2, placing a $1.6 \mathrm{~km}$ ( 1 mile) radius around the markets, and identifying those markets that had at least one census tract with a SNAP participation rate of $30 \%$ or higher in the $1.6 \mathrm{~km}$ ( 1 mile) radius. This resulted in the identification of seventeen farmers' markets and a geographic target area of $89 \mathrm{~km}^{2}\left(32.5\right.$ miles $\left.^{2}\right)$.

\section{Participant inclusion criteria}

Within this target area, inclusion criteria for individuals included: reside in targeted geographic area for $\geq 1$ year, currently receive SNAP, have child(ren) $\leq 18$ years old in the household, responsible for household food shopping, English or Spanish speaking, and age $\geq 18$ years. Only one adult per household could participate. All participants provided verbal informed consent to join the study. 


\section{Data collection procedures}

Data collection was conducted between June and August of 2015. A team of six trained study personnel conducted thirty-seven recruitment events at seventeen communitybased sites to raise awareness about the study and directly recruit. Recruitment sites focused on spaces with high numbers of SNAP or SNAP-eligible populations and included county offices where SNAP benefits and other social services were provided, emergency food assistance sites, neighbourhood centres and farmers' markets. Additionally, interested individuals could call the study phone line in response to fliers and word of mouth to join the study. Study personnel screened all interested individuals, and those eligible were invited to complete the survey. Five of the study personal were long-term residents of Greater Cleveland with experience living and/or working in the targeted study area and one was a bilingual (English/Spanish) research assistant from the university.

The study survey included close-ended items that were orally administered in person or over the telephone. Surveys took approximately $40 \mathrm{~min}$ to complete. Study personnel administered the survey using an iPad and a web-based survey program (Qualtrics) which allowed for direct entry of responses and facilitated skip patterns. Participants were compensated with a \$US 25 gift card to a local supermarket chain.

\section{Measures}

The selection of measures was guided by the Freedman multidimensional nutritious food access framework ${ }^{(25)}$, which includes five domains: spatial-temporal, economic, social, service and personal. Items relevant to these domains of food access were drawn from the literature, modelled after items in the literature or developed de novo. Selected items for the five access domains captured elements of general food shopping, farmers' market shopping and perceptions of overall food access within the neighbourhood. The survey focused mainly on fresh fruits and vegetables as markers of nutritious foods.

Spatial-temporal access is defined as geographic and time-related factors influencing nutritious food access, including perceived boundaries of the local food environment, diversity of food stores available, travel time and transportation resources, and time costs. A total of twenty-three items were identified to assess this domain. Items were drawn from the Food Choice Questionnaire ${ }^{(31)}$ and items from another study were adapted ${ }^{(32)}$.

Economic access represents financial constraints and facilitators influencing nutritious food access, including food costs, household finances, perceived value of foods in stores and the importance of store incentive programmes. Single items were drawn from prior studies $^{(31-33)}$ and two items were developed by the study team for a total of seven items to assess economic access.

Service delivery access is defined as store-level factors influencing nutritious food access, including the quality and variety of foods sold, staff and customer service, and the presentation of the food space with regard to organization and cleanliness. All items for this domain were drawn from a measure by Liese et $a l^{(32)}$ and several of these items were adapted to fit the context of the present study. A total of nineteen items were evaluated to assess service delivery access.

Social access is defined as the familial, racial and ethnic foodways and traditions influencing nutritious food access and the relationships with others around food purchasing. Items for this domain were drawn from multiple other studies ${ }^{(31-34)}$ and adapted for the present study, and several new items were developed to more fully assess the domain of social access. A total of seventeen items were evaluated.

Personal access is defined as food-related identities and preferences as well as health status that shape nutritious food access and consumption. Items to measure this domain were largely drawn and adapted from two sources $^{(33,34)}$. A total of eighteen items were evaluated to assess personal access.

All items selected to represent a domain of access were carefully reviewed by a team of four researchers to assess clarity and readability. Some stems and items were revised to simplify the wording while retaining the main concept of the item. All item stems and response formats are provided in the Results section. An example item stem for the spatial-temporal access domain is "When thinking about shopping for food, how important are the following features?' item: 'It is close to your home' and the response format was $1=$ 'not at all important', $2=$ 'somewhat important', 3 = 'important', $4=$ 'very important'. Most items had response options that fit into one of these three formats: (i) importance ( $1=$ 'not at all important', $2=$ 'somewhat important', $3=$ 'important', $4=$ 'very important'); (ii) rating quality ( $1=$ 'poor', $2=$ 'fair', $3=$ 'good', 4= 'very good', 5= 'excellent'); or (iii) agreement with statement ( $1=$ 'strongly disagree', $2=$ 'disagree', $3=$ 'neutral', $4=$ 'agree', $5=$ 'strongly agree'). The reading level of final items was 6th grade, assessed by the Fleishman test. The survey went through several cycles of pre-testing with SNAP recipients to refine the wording of items and instructions before beginning data collection.

Demographic characteristics of the participants were also assessed and included age, sex, race/ethnicity, household structure, employment status, income level and health status using standard items from the Behavioral Risk Factor Surveillance System questionnaire ${ }^{(35)}$.

\section{Analysis}

Data were entered using Qualtrics (2016; Provo, UT, USA) and were organized for analysis in the statistical software package IBM SPSS Statistics version 23. Descriptive statistics were used to report the participant characteristics.

Items for each of the five access domains were first evaluated to determine if more than one dimension was represented among the items using exploratory factor 
analysis (EFA). This approach was selected because of the a priori designation of items to assess each of the five domains of food access and the relatively modest respondent-to-item ratio (i.e. 5:1). EFA was specified with a principal axis solution and orthogonal rotation. Eigenvalues $>1 \cdot 0$, scree plots and a minimum of three or more items loading $>10 \cdot 30 \mid$ on a factor were examined to determine the number of factors. EFA was re-run limiting the number of factors and then the item loadings were examined. Items with no loading of $>10 \cdot 30 \mathrm{l}$ on a factor or having loadings of $>10.30 \mid$ on two or more factors were excluded from the final solution. For each domain identified, the internal consistency reliability was assessed using Cronbach's $\alpha$, with $\alpha<0.60$ unacceptable, $\alpha=0.65-$ 0.69 minimally acceptable, $\alpha=0.70-0.79$ respectable, $\alpha=0.80-0.89$ very good and $\alpha>0.90$ consider shortening the scale ${ }^{(36)}$. Subscale scores within each domain were computed by summing each item and dividing by the total number of items in each scale. We report the item loadings on subscales, the internal consistency reliability of each subscale, and the subscale mean, standard deviation and range.

\section{Results}

Study personnel approached 1182 individuals about the study, 910 (77.0\%) expressed interest and completed the eligibility screener, and 360 (39.6\%) were eligible to take part. Those not eligible were most frequently excluded because they did not live in the target geographic area or did not receive SNAP benefits. Of those eligible, a total of 355 individuals (98.6\%) consented to join the study and scheduled a survey appointment; and $322(90.7 \%)$ completed the survey. The remaining analyses focus on 304 participants with complete data for the specified analyses.

The characteristics of the 304 individuals who completed the survey are displayed in Table 1. The sample was predominantly female and African American. These characteristics are largely similar those of SNAP recipients in the census tracts that overlap with the geographic regions for the study with regard to the proportion of children on SNAP (2015 aggregate data by census tract from Cuyahoga County Jobs and Family Services). The study sample represents a higher proportion of females (88 v. 60\%) and substantially more African Americans (83 v. $48 \%$ ) compared with the total population of SNAP recipients from the same time period and within the same census tracts.

Tables 2-6 provide findings from the item analyses for each of the five access domains. Overall, our EFA identified that each domain is multidimensional and that all items selected to assess a domain had strong loadings on only one of the factors. Factor loadings are indicated in bold in the tables.
Table 1 Demographic and farmers' market use characteristics of the 304 survey participants, Greater Cleveland, Ohio, USA, June-August 2015

\begin{tabular}{|c|c|c|c|}
\hline Characteristic & Response category & $n$ & $\%$ \\
\hline Gender & Female & 267 & $88 \cdot 1$ \\
\hline \multirow[t]{4}{*}{ Race } & Non-Hispanic White & 27 & 8.9 \\
\hline & Non-Hispanic Black & 251 & $82 \cdot 6$ \\
\hline & Hispanic/Latino & 9 & 2.9 \\
\hline & Otherł & 17 & $5 \cdot 6$ \\
\hline \multirow[t]{4}{*}{ Age (years) } & $18-27$ & 67 & $22 \cdot 1$ \\
\hline & $28-37$ & 106 & $35 \cdot 0$ \\
\hline & $38-47$ & 61 & $20 \cdot 1$ \\
\hline & $\geq 48$ & 69 & $22 \cdot 8$ \\
\hline \multirow[t]{3}{*}{ Education } & $\leq$ Some high school & 73 & $24 \cdot 0$ \\
\hline & High-school graduate & 131 & $43 \cdot 1$ \\
\hline & College or more & 100 & $32 \cdot 9$ \\
\hline \multirow[t]{2}{*}{ Annual household income } & $<\$ \cup S 10000$ & 206 & $68 \cdot 9$ \\
\hline & $\geq \$$ US 10000 & 93 & $31 \cdot 1$ \\
\hline \multirow[t]{4}{*}{ Length of time on SNAP } & $<1$ year & 14 & 4.7 \\
\hline & $1-2$ years & 33 & $11 \cdot 0$ \\
\hline & $3-4$ years & 52 & $17 \cdot 4$ \\
\hline & $\geq 5$ years & 200 & 66.9 \\
\hline Employment* & Employed for wages & 93 & $30 \cdot 6$ \\
\hline Partnered or married status & Have partner/married & 42 & $14 \cdot 0$ \\
\hline \multirow{2}{*}{ Number of adults in home } & 1 & 182 & $60 \cdot 1$ \\
\hline & $\geq 2$ & 121 & 39.9 \\
\hline \multirow[t]{2}{*}{ Number of children in home } & $\overline{1}$ & 115 & 38.0 \\
\hline & $\geq 2$ & 188 & $62 \cdot 0$ \\
\hline \multirow[t]{5}{*}{ General health status } & $\overline{E x}$ Exellent & 31 & $10 \cdot 2$ \\
\hline & Very good & 47 & $15 \cdot 5$ \\
\hline & Good & 121 & 39.9 \\
\hline & Fair & 84 & $27 \cdot 7$ \\
\hline & Poor & 20 & $6 \cdot 6$ \\
\hline \multirow{2}{*}{$\begin{array}{l}\text { Self-reported diet-related } \\
\text { chronic disease } \dagger\end{array}$} & None & 147 & 48.4 \\
\hline & $\geq 1$ & 157 & $51 \cdot 6$ \\
\hline \multirow[t]{5}{*}{ Farmers' market use } & Never & 97 & 31.9 \\
\hline & Not in last year & 78 & $25 \cdot 7$ \\
\hline & $1-2$ times in last year & 54 & $17 \cdot 8$ \\
\hline & 3-6 times in last year & 45 & $14 \cdot 8$ \\
\hline & $\geq 7$ times in last year & 30 & 9.9 \\
\hline
\end{tabular}

SNAP, Supplemental Nutrition Assistance Program.

${ }^{\star}$ Employed status means that participants are employed with wages.

tOne or more chronic disease means that participants self-reported having at least one chronic condition among obesity, diabetes, high blood pressure, cancer and other chronic conditions.

fOther category included multiple responses (e.g. 'Yes' for both White and Black).

\section{Exploratory factor analyses}

Spatial-Temporal Access domain

The twenty-three items selected to measure spatialtemporal access were subjected to EFA and four sub-domains emerged (Table 2). Sub-domain Importance of Food Procurement and Preparation Convenience (nine items) includes items about the food access point being close to home or work, that it is easy to get there, and the ease of preparation of the foods. Healthy Food Availability (four items) includes items specific to the quality, affordability and selection of fruits and vegetables in the neighbourhood. Ease of Access to Farmers' Markets (four items) includes items about being close to home and public transportation and it is easy to get there. The final sub-domain, Time Costs of Foods Purchased and Consumed (four items), includes items that measure lack of time to cook and shop and that it is not convenient to buy fruits and vegetables. 
Table 2 Factor and item analysis of Spatial-Temporal Access domain items and resulting four sub-domains

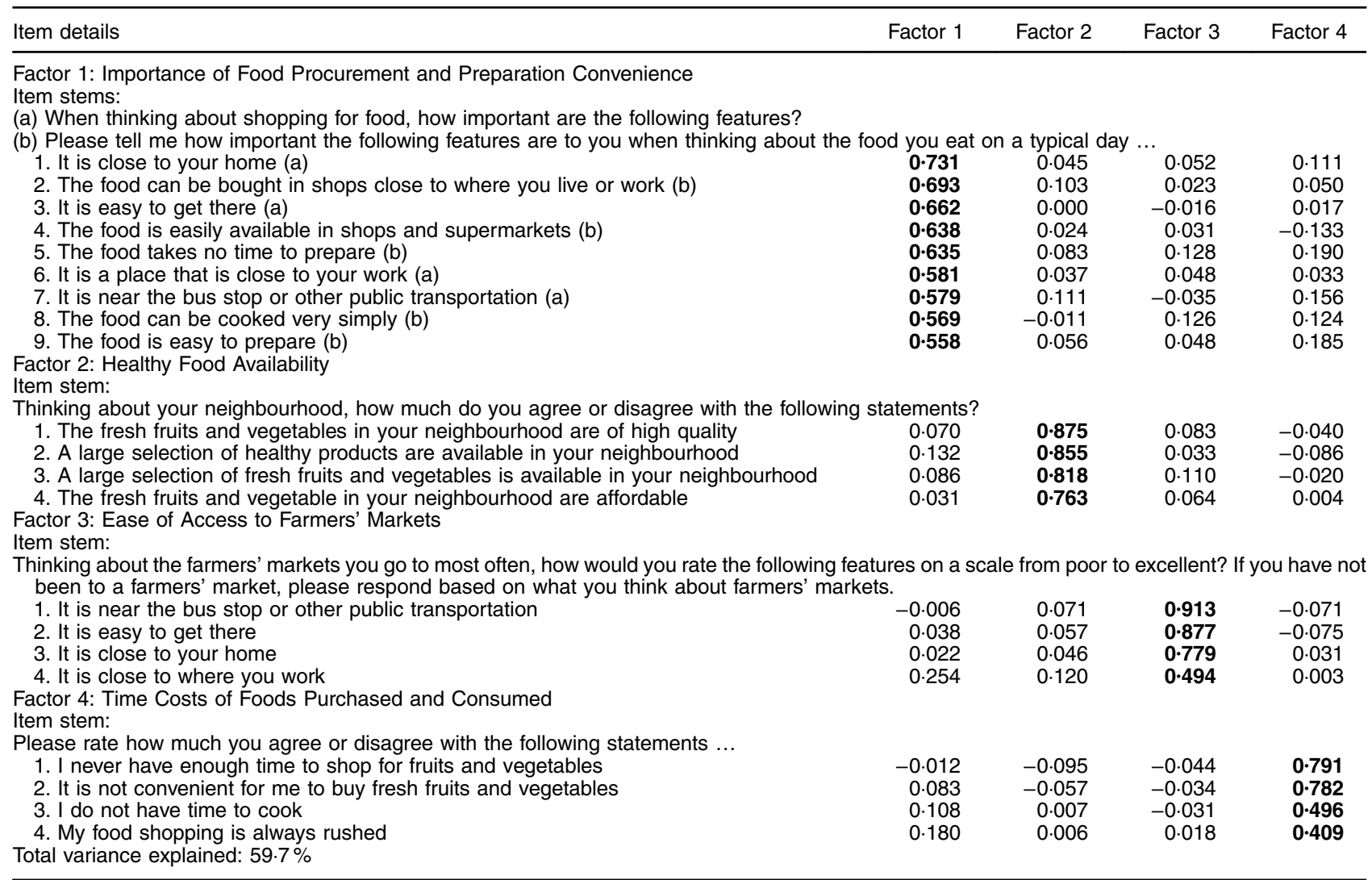

Factor loadings are indicated in bold.

Response formats: importance ( $1=$ 'not at all', $2=$ 'somewhat important', $3=$ 'important', $4=$ 'very important'); rating quality $(1=$ 'poor', $2=$ 'fair', 3 = 'good', 4 = 'very good', 5 = 'excellent'); agreement with statement ( $1=$ 'strongly disagree', $2=$ 'disagree', $3=$ 'neutral', $4=$ 'agree', $5=$ 'strongly agree').

Table 3 Factor and item analysis of Economic Access domain items and resulting two sub-domains

\begin{tabular}{lcc}
\hline Item details & Factor 1 & Factor 2 \\
\hline Factor 1: Value of Farmers' Markets for Money & & \\
Item stem: & & \\
Thinking about the farmers' markets you go to most often, how would you rate the following features on a scale from poor to excellent? If you \\
have not been to a farmers' market, please respond based on what you think about farmers' markets. & 0.102 \\
1. It has good prices & $\mathbf{0 . 9 1 6}$ & 0.047 \\
2. It accepts EBT/Ohio Direction Card or WIC & $\mathbf{0 . 6 2 7}$ & 0.105 \\
3. It has coupons/good deals & $\mathbf{0 . 6 2 7}$ &
\end{tabular}

Factor 2: Prices of Foods Purchased and Consumed

Item stems:

(a) Please tell me how important the following features are to you when thinking about the food you eat on a typical day ...

(b) When thinking about shopping for food, how important are the following features?

1. The food is a good value for your money (a)

2. The food is cheap/inexpensive (a)

3. It is a place that has coupons or good deals (b)

Total variance explained by two factors: $61.7 \%$

$\begin{array}{ll}0.025 & \mathbf{0 . 8 4 7} \\ 0.021 & \mathbf{0 . 5 1 3} \\ 0.137 & \mathbf{0 . 3 7 4}\end{array}$

EBT, electronic benefit card; WIC, Special Supplemental Nutrition Program for Women, Infants, and Children.

Factor loadings are indicated in bold.

Response formats: importance ( $1=$ 'not at all', $2=$ 'somewhat important', $3=$ 'important', $4=$ 'very important'); rating quality $(1=$ ='poor', $2=$ 'fair', $3=$ 'good', $4=$ 'very good', $5=$ 'excellent').

Together, these four sub-domains explain $60 \%$ of the variance among the items.

\section{Economic Access domain}

Economic access was assessed by seven items and the EFA identified two sub-domains. Sub-domain Value of Farmers'
Markets for Money (three items) includes items about perception of good prices, accepts the Ohio Direction Card (i.e. SNAP card in Ohio) and has coupons and good deals (Table 3). The second sub-domain, Prices of Foods Purchased and Consumed, is also represented by three items. The focus of these items is on the 
Table 4 Factor and item analysis of Service Delivery domain items and resulting two sub-domains

\begin{tabular}{|c|c|c|}
\hline Item details & Factor 1 & Factor 2 \\
\hline \multicolumn{3}{|c|}{$\begin{array}{l}\text { Factor 1: Service Delivery at Farmers' Markets } \\
\text { Item stem: }\end{array}$} \\
\hline \multicolumn{3}{|c|}{$\begin{array}{l}\text { Thinking about the farmers' markets you go to most often, how would you rate the following features on a scale from poor to excellent? If you } \\
\text { have not been to a farmers' market, please respond based on what you think about farmers' markets. }\end{array}$} \\
\hline 1. It is neat and organized & 0.882 & 0.012 \\
\hline 2. It has good-quality fruits and vegetables & 0.865 & 0.059 \\
\hline 3. It is clean & $0 \cdot 857$ & 0.041 \\
\hline 4. It has a variety of healthy food options & 0.817 & 0.054 \\
\hline 5. It sells food that you want to buy & 0.802 & 0.117 \\
\hline 6. It provides good customer service & 0.777 & 0.005 \\
\hline 7. It has organic and/or locally grown food & 0.759 & 0.074 \\
\hline 8. It allows you to do one-stop shopping & 0.676 & 0.085 \\
\hline 9. It has open hours that fit your schedule & 0.669 & 0.155 \\
\hline 10. It has good-quality meat products & 0.629 & 0.122 \\
\hline 11. It has a wide variety of food and non-food products & 0.528 & 0.097 \\
\hline \multicolumn{3}{|l|}{$\begin{array}{l}\text { Factor 2: Importance of Food Store Qualities } \\
\text { Item stem: }\end{array}$} \\
\hline \multicolumn{3}{|l|}{ When thinking about shopping for food, how important are the following features? } \\
\hline 1. It is neat and organized & 0.105 & 0.799 \\
\hline 2. It is clean & 0.050 & 0.738 \\
\hline 3. It has good-quality fruits and vegetables & 0.154 & 0.654 \\
\hline 4. It provides good customer service & 0.009 & 0.650 \\
\hline 5. It has good-quality meat products & -0.033 & 0.566 \\
\hline 6. It has a variety of healthy food options & 0.174 & 0.471 \\
\hline 7. It has open hours that fit your schedule & 0.006 & 0.392 \\
\hline 8. It has wide variety of food and non-food products (e.g. diapers, toiletries) & 0.061 & 0.373 \\
\hline Total variance explained: $54.2 \%$ & & \\
\hline
\end{tabular}

Factor loadings are indicated in bold.

Response formats: importance ( $1=$ 'not at all', $2=$ 'somewhat important', $3=$ 'important', $4=$ 'very important'); rating quality ( $1=$ 'poor', $2=$ 'fair', $3=$ 'good', 4 = 'very good', 5 = 'excellent').

Table 5 Factor and item analysis of Social Access domain items and resulting three sub-domains

Factor 1: Social Connectedness to Farmers' Markets

Item stems:

(a) Thinking about the farmers' markets you go to most often, how would you rate the following features on a scale from poor to excellent? If you have not been to a farmers' market, please respond based on what you think about farmers' markets.

(b) Please rate how much you agree or disagree with the following statements ...

1. You feel welcome when you shop there (a)

2. Other customers at the farmers' market will be friendly (a)

3. It is familiar to you (a)

4. The people you're close to shop there (a)

5. You like the people there (a)

6. Members of my family think that it is a good idea to buy food at farmers' markets (b)

7. Most of my friends and acquaintances think that shopping for food at farmers' market is a good idea (b)

Factor 2: Food Culture and Food Store Relationships

Item stems:

(a) When thinking about shopping for food, how important are the following features?

(b) Please tell me how important the following features are to you when thinking about the food you eat on a typical day...

1. The people you're close to shop there (a)

2. The food is like the food you ate when you were a child (b)

3. The food is familiar (b)

4. The food is what you usually eat (b)

5. You feel welcome when you shop there (a)

6. You like the people there (a)

Factor 3: Healthy Eating Social Networks

Item stem:

Among the people close to you in Cleveland, please answer for these features:

1. How many have used EBT/Ohio Direction Card at a farmers' market in the past year?

2. How many have shopped at a farmers' market in the past year?

3. How many have used Produce Perks in the past year?

4. How many have participated in nutrition education classes in the past year? Total variance explained: $56 \cdot 2 \%$

$\begin{array}{llr}\mathbf{0 . 8 8 6} & 0.082 & -0.038 \\ \mathbf{0 . 8 5 0} & 0.137 & 0.022 \\ \mathbf{0 . 8 1 9} & 0.080 & -0.005 \\ \mathbf{0 . 7 4 1} & 0.081 & 0.325 \\ \mathbf{0 . 7 3 7} & 0.056 & 0.005 \\ \mathbf{0 . 4 2 9} & 0.084 & 0.179 \\ \mathbf{0 . 3 4 9} & 0.225 & 0.171\end{array}$

EBT, electronic benefit card.

Factor loadings are indicated in bold.

Response formats: importance $(1=$ 'not at all', $2=$ 'somewhat important', $3=$ ' important', $4=$ =very important'); rating quality $(1=$ 'poor', $2=$ 'fair', $3=$ 'good', $4=$ 'very good', $5=$ 'excellent'); agreement with statement ( $1=$ 'strongly disagree', $2=$ 'disagree', $3=$ 'neutral', $4=$ 'agree', $5=$ 'strongly agree'); among the people close to you in Cleveland ( $1=$ 'none', $2=$ 'less than half', $3=$ 'about half', $4=$ ='more than half', $5=$ 'all'). 
Table 6 Factor and item analysis of Personal Access domain items and resulting three sub-domains

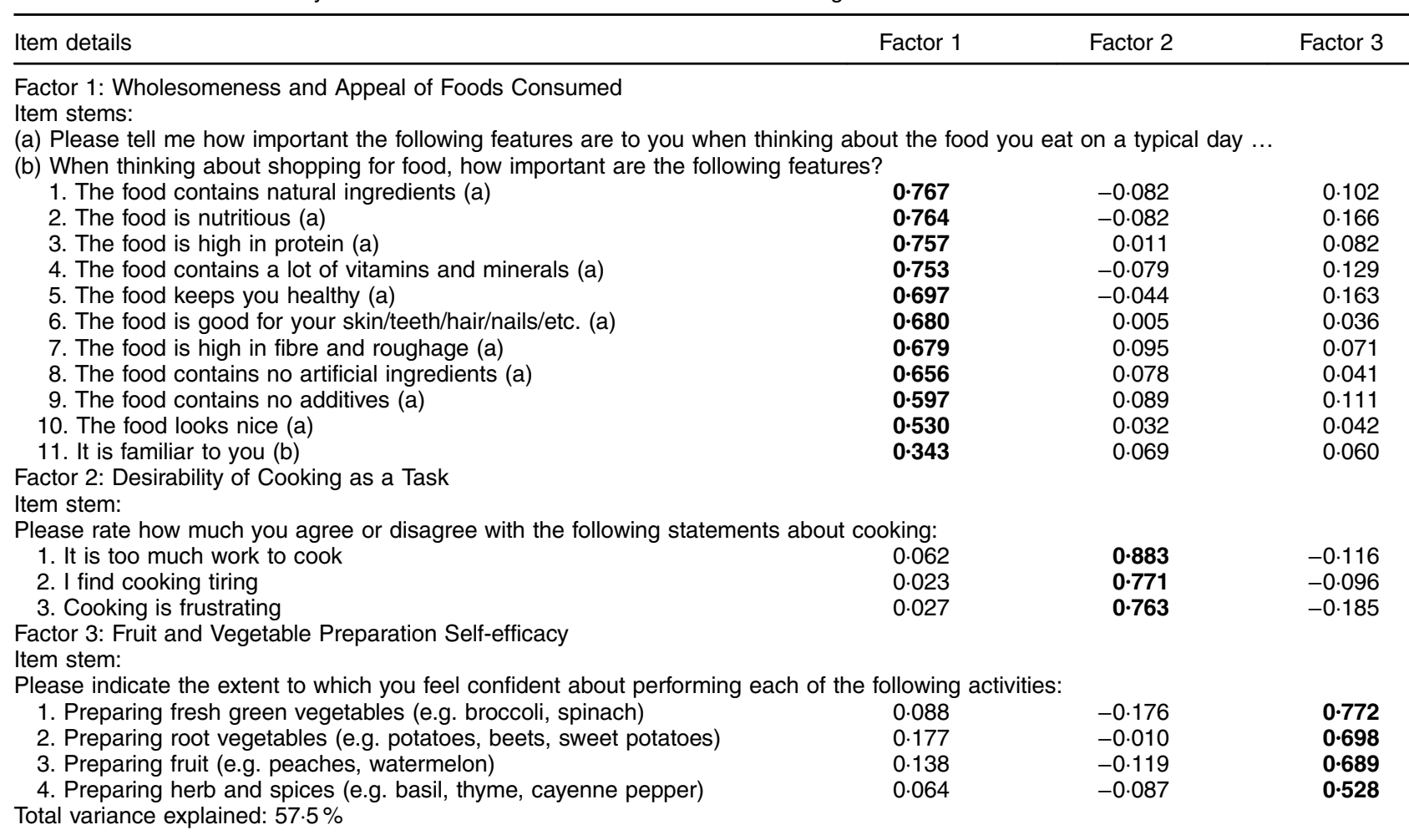

Factor loadings are indicated in bold.

Response formats: importance ( $1=$ 'not at all', 2 = 'somewhat important', 3 =' important', 4 = 'very important'); agreement with statement ( 1 = 'strongly disagree', 2 = 'disagree', $3=$ 'neutral', $4=$ 'agree', $5=$ 'strongly agree'); confidence ( $1=$ 'not at all confident', $2=$ 'not very confident', $3=$ 'neutral', $4=$ 'confident', $5=$ 'extremely confident').

food eaten on a typical day and the importance of value for money and being inexpensive, and for general food shopping the importance of having coupons or good deals. One item did not meaningfully contribute and was dropped from further consideration. The two factors explained $62 \%$ of the variance among the economic access items.

\section{Service Delivery domain}

Analysis of the nineteen items selected to measure service delivery resulted in two factors (Table 4). Service Delivery at Farmers' Markets is represented by eleven items that cover quality and variety of products and aspects of the shopping experience, like hours of shopping and customer service. The second factor, Importance of Food Store Qualities, includes eight items that rate the importance of quality and variety of products, and aspects of the shopping experience for general food shopping. These items parallel the items in the first factor. Overall, these two factors explain $54 \%$ of the variance.

\section{Social Access domain}

Social access was assessed with seventeen items and the EFA identified three factors (Table 5). Social Connectedness to Farmers' Markets includes seven items representing feeling welcome, familiarity and having social relations with the people there. The second factor, Food Culture and Food Store Relationships, is represented by six items in the context of food shopping and the food eaten on a typical day and the importance of familiarity of foods and people. The last social access factor is Healthy Eating Social Networks and is represented by four items. The items on this sub-domain assess the number of people close to the respondent who have engaged in specific healthy eating activities: using the Ohio Direction Card at a farmers' market, shopped at a farmers' market, have used an incentive programme at a farmers' market or have been engaged in nutritional education classes. For the social access items, these three factors explain $56 \%$ of variance.

\section{Personal Access domain}

A total of eighteen items were used to assess personal access and EFA identified three factors (Table 6). Wholesomeness and Appeal of Foods Consumed is represented by eleven items about nutrients and overall appeal of the food eaten on a typical day. The second factor, Desirability of Cooking as a Task, includes three items about cooking as too much work, tiring or frustrating. The third factor is Fruit and Vegetable Preparation Self-efficacy, which includes four items and represents the degree of confidence in preparing fruits and vegetables. The variance explained by these three factors of personal access is $57 \%$. 


\section{Summary statistics}

The summary statistics including the number of items, the internal consistency reliability and descriptive statistics (mean, standard deviation and range) for each of the subdomains is presented in Table 7. Of the fourteen scored sub-domains, one had outstanding Cronbach's $\alpha$ internal consistency reliability greater than 0.90 , seven had excellent internal consistency reliability between 0.80 and 0.89 , and five had very good internal consistency reliability between 0.70 and 0.79 . One scale, the Prices of Foods Purchased and Consumed, had low internal consistency reliability of $0 \cdot 58$. Overall, the internal consistency reliability values for these relatively short subscales are high, indicating the number of items per sub-domain may be reduced and still maintain an acceptable internal consistency of $0 \cdot 80$. For example, for the nine-item Importance of Food Procurement and Preparation Convenience scale within the spatial-temporal domain can be reduced to a four-item scale and maintain an internal consistency reliability of $0 \cdot 80$. However, given the preliminary nature of these measures that they are based on a single sample, we do not present further information on the reduced scales.

\section{Discussion}

The findings of the present study support the proposition that perception of access to nutritious foods is a multidimensional concept; the five proposed domains of access can be represented as multiple sub-domains; and each can be measured using self-report items with good reliability. All sub-domains, except for the Prices of Foods Purchased and Consumed subscale of economic access, met an acceptable level of reliability. We found that the Freedman conceptual framework of access to nutritious food ${ }^{(25)}$, consisting of spatial-temporal, economic, social, service and personal access, for venues of general food shopping and farmers' markets can be robustly measured using eighty-one items representing fourteen subscales. The access to healthy food subscales reported in the present paper were created by combining items from multiple sources and adapting them to reflect both general food stores and farmers' markets $^{(31-34,37,38)}$ and from unpublished research from our team.

Our analyses further revealed that for many of the subscales the number of items per scale may be reduced and still maintain an acceptable internal consistency of $0 \cdot 80$. For example, for the Service Delivery at Farmers' Markets subscale, the eleven items can be reduced to six items and maintain an internal consistency reliability of $0 \cdot 80$. Shorter assessment tools have pragmatic appeal for some research or evaluation needs because they can reduce participant burden and the cost of assessing the concept ${ }^{(39)}$.

The current work adds substantially to the ability to assess multiple domains of food access and to measure access specific to farmers' markets. The measures presented herein can be particularly useful to inform the design and targeting of interventions to increase access to nutritious foods and can also be used to evaluate perceptions of access among a variety of groups. For example, if assessments using these measures indicate low levels of social access among a subgroup, this might point to interventions specifically designed to increase perceptions of social access within existing food retailers. As another example, our team used the scores on the measures to guide purposive sampling for inclusion in a qualitative study to gain deeper insight into individuals' social networks, understanding of food environments and practices of procuring and preparing food.

While the survey items were designed for use with a lowincome population, the content and the reading level are relevant and accessible to all groups. Likewise, the study team chose to focus a substantial number of the items on farmers' markets because of the growing prevalence and keen interest in their impact on fruit and vegetable consumption in our region. We envision that the subscales to assess the conceptual framework of access to nutritious foods presented here could be tailored and used in other contexts important to food access such as corner stores or

Table 7 Summary statistics for each of the sub-domain scores

\begin{tabular}{|c|c|c|c|c|c|c|c|}
\hline Domain & Subdomain & $\begin{array}{l}\text { No. of } \\
\text { items }\end{array}$ & $\begin{array}{c}\text { Internal } \\
\text { consistency } a\end{array}$ & $\begin{array}{l}\text { Score } \\
\text { mean }\end{array}$ & SD & Min. & Max. \\
\hline \multirow[t]{4}{*}{$\begin{array}{l}\text { Spatial-Temporal } \\
\text { Access }\end{array}$} & $\begin{array}{l}\text { 1. Importance of Food Procurement and Preparation } \\
\text { Convenience }\end{array}$ & 9 & $0 \cdot 86$ & $3 \cdot 2$ & 0.7 & 1.4 & $4 \cdot 0$ \\
\hline & 2. Healthy Food Availability & 4 & 0.89 & 3.4 & $1 \cdot 1$ & 1.0 & $5 \cdot 0$ \\
\hline & 3. Ease of Access to Farmer's Market & 4 & 0.85 & 3.5 & $1 \cdot 1$ & 1.0 & $5 \cdot 0$ \\
\hline & 4. Time Costs of Foods Purchased and Consumed & 4 & 0.74 & 1.9 & 0.8 & 1.0 & 4.5 \\
\hline \multirow[t]{2}{*}{ Economic Access } & 1. Value of Farmers' Markets for Money & 3 & 0.76 & 3.9 & 0.9 & 1.0 & $5 \cdot 0$ \\
\hline & 2. Prices of Foods Purchased and Consumed & 3 & 0.58 & $3 \cdot 4$ & 0.6 & $1 \cdot 3$ & $4 \cdot 0$ \\
\hline \multirow{2}{*}{$\begin{array}{l}\text { Service Delivery } \\
\text { Access }\end{array}$} & 1. Service Delivery at Farmers' Markets & 11 & 0.94 & $3 \cdot 8$ & 0.9 & 1.0 & 5.0 \\
\hline & 2. Importance of Food Store Qualities & 8 & 0.84 & 3.7 & 0.4 & 1.0 & 4.0 \\
\hline \multirow[t]{3}{*}{ Social Access } & 1. Social Connectedness to Farmer's Markets & 7 & 0.86 & $3 \cdot 8$ & 0.8 & 1.6 & $5 \cdot 0$ \\
\hline & 2. Food Culture and Food Store Relationships & 6 & 0.78 & $3 \cdot 1$ & 0.7 & $1 \cdot 3$ & 4.0 \\
\hline & 3. Healthy Eating Social Networks & 4 & 0.78 & $2 \cdot 3$ & 0.9 & 1.0 & $4 \cdot 8$ \\
\hline \multirow[t]{3}{*}{ Personal Acess } & 1. Wholesomeness and Appeal of Foods Consumed & 11 & 0.89 & $3 \cdot 4$ & 0.6 & $1 \cdot 1$ & $4 \cdot 0$ \\
\hline & 2. Desirability of Cooking as a Task & 3 & 0.78 & 1.9 & 0.9 & 1.0 & 5.0 \\
\hline & 3. Fruit and Vegetable Preparation Self-efficacy & 4 & 0.86 & 4.4 & 0.7 & 1.3 & $5 \cdot 0$ \\
\hline
\end{tabular}


other types of food outlets. Using robust measures of multiple aspects of food access, such as the measure presented in the current research, in studies conducted in a wide range of contexts would greatly advance our understanding of underlying access facilitators and barriers.

In considering the use of the measures presented, subscales can be used in whole or part depending on the goals of the project, research questions and the feasible length of survey. Further, as noted earlier, some of the scales could be shortened with no or small reduction in internal consistency reliability. Before such reduction, the subscales should be subjected to additional testing with larger samples across varied contexts to inform how items perform across settings; and item reduction should be equally informed by maintaining the content coverage of the scale and by avoiding efforts to maximize internal consistency at the risk of severely restricting the breadth of coverage of the concept.

Use of the measures in other geographic settings, food environment contexts and with other populations (e.g. different proximity to farmers' markets, individuals with different or no supplemental benefits, those living in lessdense farmers' market environments, different income levels) will greatly contribute to the evaluation and utility of the subscales for continued application. Indeed, additional testing of the items and subscales in different contexts is warranted to build evidence for the validity and reliability of these measures and to understand how they perform across types of survey participants. Of particular value would be studies designed to test the construct and predictive validity of the subscales; such work is necessary to build additional evidence for the utility of each subscale and can help inform the selection of items to retain for future study.

\section{Limitations}

The limitations of the present study include the modest sample size of 304 participants and the homogeneous sampling frame of individuals who receive SNAP and who live within a specific geographic location. This measurement development work is part of a larger study with a focus on food access in this population, which thus drove the sampling frame for the measurement development phase. This sample, therefore, represents individuals who are likely to have greater restrictions on nutritious food access and are therefore those with whom the development of interventions to improve food access is of high interest. Establishing measures that are reliable and sensitive to change among this population is necessary. A second limitation is that the study was conducted in an urban community with high access to farmers' markets. Awareness and use of farmers' markets may be higher among this sample, and frequency of use may be associated with scores on perceptions of quality and access. It is unlikely to have an impact on the underlying structure of the concepts or the reliability with which the sub-domains in the measure are assessed. Finally, future work should assess objective indicators including distance to food purchasing locations and food purchasing behaviours so that their association with measures of multidimensional food access can be evaluated.

\section{Conclusions}

Multiple levels of food access can be assessed with short measures with good internal consistency. The measures evaluated in the present study may be used in future studies to measure the complex phenomenon of nutritious food access more accurately and robustly.

\section{Acknowledgements}

Acknowledgements: The authors wish to thank the community members who completed the survey, the community partners that supported recruitment and the team of data collectors. Financial support: This publication is a product of a Health Promotion and Disease Prevention Research Center supported by Cooperative Agreement Number 1U48DP005030 from the Centers for Disease Control and Prevention. The findings and conclusions in this publication are those of the authors and do not necessarily represent the official position of the Centers for Disease Control and Prevention. The Centers for Disease Control and Prevention had no role in the design, analysis or writing of this article. Conflict of interest: The authors have no conflicts of interest to declare. Authorship: S.A.F. contributed to the design and implementation of the study, data analyses and interpretation of the findings, and writing of the manuscript; P.O.-V. contributed to the study design, interpretation of the findings and to multiple drafts of the manuscript; E.-J.S. assisted with data analyses, generation of tables, and contributed to the methods and results sections; E.S.T. contributed to interpretation of the findings and to multiple drafts of the manuscript; E.B. contributed to interpretation of the findings and to multiple drafts of the manuscript; K.M. contributed to the implementation of the study, survey development and to the methods section; and D.A.F. contributed to the design and implementation of the study, interpretation of the findings and to all sections of the manuscript. Ethics of buman subject participation: This study was conducted according to the guidelines laid down in the Declaration of Helsinki and all procedures involving human participants were approved by the Case Western Reserve University Institutional Review Board. Verbal informed consent was obtained from all participants. Verbal consent was witnessed and formally recorded.

\section{References}

1. Swinburn BA, Millar L, Utter J et al. (2011) The Pacific Obesity Prevention in Communities project: project overview and methods. Obes Rev 12, Suppl. 2, 3-11. 
2. Ogden CL, Carroll MD, Fryar CD et al. (2015) Prevalence of obesity among adults and youth: United States, 2011-2014. NCHS Data Brief issue 219, 1-8.

3. Lake A \& Townshend T (2006) Obesogenic environments: exploring the built and food environments. J R Soc Promot Health 126, 262-267.

4. Swinburn B \& Egger G (2002) Preventive strategies against weight gain and obesity. Obes Rev 3, 289-301.

5. US Department of Agriculture \& US Department of Health and Human Services (2010) Dietary Guidelines for Americans, 2010. Washington, DC: USDA and US DHHS; available at http://www.health.gov/dietaryguidelines/dga2010/Dietary Guidelines2010.pdf

6. Dutko P, Ver Ploeg M \& Farrigan T (2012) Characteristics and Influential Factors of Food Deserts. Washington: DC: US Department of Agriculture, Economic Research Service; available at http://www.ers.usda.gov/media/883903/err140. pdf

7. Ellaway A \& Macintyre S (1996) Does where you live predict health related behaviours?: a case study in Glasgow. Health Bull (Edinb) 54, 443-446.

8. Walker RE, Keane CR \& Burke JG (2010) Disparities and access to healthy food in the United States: a review of food deserts literature. Health Place 16, 876-884.

9. Walker RE \& Kawachi I (2012) Use of concept mapping to explore the influence of food security on food buying practices. J Acad Nutr Diet 112, 711-717.

10. Giskes K, Van Lenthe FJ, Brug J et al. (2007) Socioeconomic inequalities in food purchasing: the contribution of respondent-perceived and actual (objectively measured) price and availability of foods. Prev Med 45, 41-48.

11. Chung C \& Myers S (1999) Do the poor pay more for food? An analysis of grocery store availability and food price disparities. J Consum Aff 33, 276-296.

12. Zenk SN, Powell LM, Rimkus L et al. (2014) Relative and absolute availability of healthier food and beverage alternatives across communities in the United States. $A m \mathrm{~J}$ Public Health 104, 2170-2178.

13. Rimkus L, Isgor Z, Ohri-Vachaspati P et al. (2015) Disparities in the availability and price of low-fat and higher-fat milk in US food stores by community characteristics. I Acad Nutr Diet 115, 1975-1985.

14. Beauchamp A, Backholer K, Magliano D et al. (2014) The effect of obesity prevention interventions according to socioeconomic position: a systematic review. Obes Rev $\mathbf{1 5}$, 541-554.

15. Ohri-Vachaspati P \& Leviton LC (2010) Measuring food environments: a guide to available instruments. Am J Health Promot 24, 410-426.

16. McKinnon RA, Reedy J, Morrissette MA et al. (2009) Measures of the food environment: a compilation of the literature, 1990-2007. Am J Prev Med 36, 4 Suppl., S124-S133.

17. Glanz K, Sallis JF, Saelens BE et al. (2007) Nutrition Environment Measures Survey in stores (NEMS-S): development and evaluation. Am J Prev Med 32, 282-289.

18. Izumi BT, Zenk SN, Schulz AJ et al. (2012) Inter-rater reliability of the Food Environment Audit for Diverse Neighborhoods (FEAD-N). J Urban Health 89, 486-499.

19. Rimkus L, Powell LM, Zenk SN et al. (2013) Development and reliability testing of a food store observation form. J Nutr Educ Behav 45, 540-548.

20. Truong K, Fernandes M, An R et al. (2010) Measuring the physical food environment and its relationship with obesity: evidence from California. Public Health 124, 115-118.

21. Dibsdall L, Lambert N, Bobbin R et al. (2003) Low-income consumers' attitudes and behaviour towards access, availability and motivation to eat fruit and vegetables. Public Health Nutr 6, 159-168.

22. Echeverria SE, Diez-Roux AV \& Link BG (2004) Reliability of self-reported neighborhood characteristics. J Urban Health 81, 682-701.

23. Cummins S (2007) Neighbourhood food environment and diet - time for improved conceptual models? Prev Med 44, 196-197.

24. Lytle LA (2009) Measuring the food environment. State of the science. Am J Prev Med 36, Suppl. 4, S134-S144.

25. Freedman DA, Blake CE \& Liese AD (2013) Developing a multicomponent model of nutritious food access and related implications for community and policy practice. J Community Pract 21, 379-409.

26. Centers for Disease Control and Prevention (2011) Strategies to Prevent Obesity and Other Chronic Diseases: The CDC Guide to Strategies to Increase the Consumption of Fruits and Vegetables. Atlanta, GA: CDC; available at http://www. cdc.gov/obesity/downloads/FandV_2011_WEB_TAG508. pdf

27. Committee on Accelerating Progress in Obesity Prevention, Food and Nutrition Board, Institute of Medicine (2012) Accelerating Progress in Obesity Prevention: Solving the Weight of the Nation [D Glickman, L Parker, LJ Sim et al., editors]. Washington, DC: National Academies Press; available at http://www.nationalacademies.org/hmd/Reports/ 2012/Accelerating-Progress-in-Obesity-Prevention.aspx

28. US Census Bureau (2015) American Community Profiles. https://www.census.gov/acs/www/data/data-tables-andtools/data-profiles/2015/ (accessed December 2016)

29. US Department of Agriculture, Economic Research Service (2016) Food Access Research Atlas. http://www.ers.usda gov/data-products/food-access-research-atlas.aspx (accessed December 2016).

30. Walsh CC, Taggart M, Freedman DA et al. (2015) The Cleveland-Cuyahoga county food policy coalition: 'we have evolved'. Prev Chronic Dis 12, E86.

31. Steptoe A, Pollard TM \& Wardle J (1995) Development of a measure of the motives underlying the selection of food: the Food Choice Questionnaire. Appetite 25, 267-284.

32. Liese AD, Bell BA, Barnes TL et al. (2014) Environmental influences on fruit and vegetable intake: results from a path analytic model. Public Health Nutr 17, 2595-2604.

33. Leone LA, Beth D, Ickes SB et al. (2012) Attitudes toward fruit and vegetable consumption and farmers' market usage among low-Income North Carolinians. J Hunger Environ Nutr 7, 64-76.

34. Thompson KE, Haziris N \& Alekos PJ (1994) Attitudes and food choice behaviour. Br Food J 96, 9-13.

35. Centers for Disease Control and Prevention (2013) 2013 Behavioral Risk Factor Surveillance System Questionnaire. Atlanta, GA: CDC

36. DeVellis RF (1991) Reliability. In Scale Development: Theory and Applications, pp. 24-42. Thousand Oaks, CA: SAGE Publications, Inc.

37. Mujahid MS, Diez Roux AV, Morenoff JD et al. (2007) Assessing the measurement properties of neighborhood scales: from psychometrics to ecometrics. Am J Epidemiol 165, 858-867.

38. Middleton C \& Smith S (2011) Purchasing habits of senior farmers' market shoppers: utilizing the theory of planned behavior. J Nutr Gerontol Geriatr 30, 248-260.

39. Glasgow RE \& Riley WT (2013) Pragmatic measures. Am J Prev Med 45, 237-243. 